\title{
Dysautonomia in the synucleinopathies: not just orthostatic hypotension
}

\author{
Jose-Alberto Palma ${ }^{1}$
}

Received: 14 October 2019 / Accepted: 15 October 2019 / Published online: 24 October 2019

๑) Springer-Verlag GmbH Germany, part of Springer Nature 2019

In contrast to other abnormally misfolded proteins that accumulate in the nervous system and are associated with its degeneration (e.g., tau in Alzheimer disease and progressive supranuclear palsy, TDP-43 in amyotrophic lateral sclerosis and frontotemporal dementia, or huntingtin in Huntington disease), alpha-synuclein is one of the few that accumulates in the autonomic nervous system, centrally and peripherally, causing generalized autonomic failure, one of the most disabling non-motor features of Parkinson disease (PD) and other synucleinopathies. Among the best-known and better described features of synuclein-mediated autonomic failure is neurogenic orthostatic hypotension $(\mathrm{nOH})$, which results from inappropriate norepinephrine release from efferent sympathetic postganglionic fibers innervating the blood vessels when standing up. The increasing attention to $\mathrm{nOH}$ is well deserved given its significant morbidity and the availability of FDA-approved therapies [10]. Autonomic failure in the synucleinopathies, though, affects organs and systems other than the blood vessels, including the heart, the skin and sweat glands, and the gastrointestinal and genitourinary systems.

This issue of Clinical Autonomic Research aims to bring attention to manifestations of autonomic failure in the synucleinopathies other than $\mathrm{nOH}$ by putting together original contributions, review articles, and editorial comments from a dazzling group of world-renowned experts in the field.

The issue begins with the Streeten Lecture that Dr. Eduardo Benarroch gave at the 2019 meeting of the American Autonomic Society [1]. Dr. Benarroch highlights how multiple system atrophy (MSA), the most aggressive of the synucleinopathies, preferentially targets the brainstem, thus

Jose-Alberto Palma

clinicalautonomicresearch@gmail.com

1 Department of Neurology, Dysautonomia Center, New York University School of Medicine, 530 First Avenue, Suite 9Q, New York, NY 10016, USA affecting not just cardiovascular but also respiratory and arousal/sleep functions, which are crucial for survival.

In their state-of-the-art review, Sklerov and colleagues summarize the use of advance functional neuroimaging to further understand the central autonomic network in the synucleinopathies [13]. The review is accompanied by an introductory comment by Prof. Vaughan Macefield, a pioneer in the use of functional neuroimaging in autonomic medicine [9].

Continuing with neuroimaging, but this time of the heart, Brandle and Braune [2] show that, because cardiac sympathetic denervation is virtually universal in patients with $\mathrm{PD}$, using cardiac MIBG improves the diagnostic accuracy for PD of clinical diagnostic examination alone. MIBG is widely available in Europe but is regrettably much less performed in the US, mostly for insurance reasons. Works like this should contribute to advocate for the use of MIBG for the differential diagnosis of parkinsonism in the US.

An increasingly relevant topic is the detection of alphasynuclein in skin nerves. Skin biopsy is relatively little invasive (as compared to other biomarkers sources, such as CSF analysis) and there is mounting interest by multiple research groups to define if it can improve the diagnostic accuracy of the synucleinopathies. Dr. Vincenzo Donadio, a pioneer in synuclein detection in skin, writes an authoritative review summarizing the advances in this technique, emphasizing the existing challenges [6]. A comment by Dr. Lola Vilas, an expert in alpha-synuclein detection in peripheral tissues [15], introduces Donadio's review.

Isonaka, Goldstein and colleagues combine the techniques of alpha-synuclein detection in skin biopsy and cardiac 18F-dopamine neuroimaging to show a tight correlation between alpha-synuclein deposition in arrector pilli muscles and cardiac noradrenergic deficits in patients with synucleinopathies [8]. This work is certainly exceptional: Goldstein's group is one of the few in the world with access to cardiac $18 \mathrm{~F}$-dopamine neuroimaging to quantify cardiac sympathetic innervation. 
Drooling is an under-recognized complain in patients with synucleinopathies. In a large cross-sectional study in Chinese patients with MSA, Yanming and colleagues showed that drooling is present in up to $60 \%$ of patients with MSA, and it is associated with more advanced markers of disease progression [4]. Increased recognition of drooling should result in improved therapeutic options for patients with this debilitating symptom.

In spite of their limitations, heart rate variability is still extensively used to understand vagal and baroreflex tone. Carricarte Naranjo and colleagues performed advanced HRV analysis in patients with PD and carriers with the mutations in the gene most commonly affected in the disease, LRRK2 [3]. Interestingly, mutations in this gene have been also found in some patients with PSP and, more recently, in patients with MSA $[11,16]$. This has therapeutic implications because therapies targeting LRRK2 are now in the pipeline [17].

Deep brain stimulation (DBS) has been used for decades to improve motor dysfunction in patients with PD. Although the most common target of the DBS is the subthalamic nucleus, the pedunculopontine nucleus (PPN) is emerging as area of interest. In their innovative work, Green and colleagues showed that stimulation of the PPN might be associated with cardiovascular changes [7]. Although their sample size is small and further studies are required, their results are encouraging and may represent a novel therapeutic avenue for baroreflex dysfunction in patients with synucleinopathies.

Finally, Sakakibara and colleagues focus on bladder and bowel disturbances in the synucleinopathies. In a significant work, they describe a series of patients with MSA whose first manifestation of the disease was bladder dysfunction [12]. This has diagnostic implications, particularly that improved diagnostic criteria for MSA are underway [14]. Finally, in a second work, they studied, for the first time, gastric emptying in patients with dementia with Lewy bodies [5]. Not surprisingly, they found that gastrointestinal emptying was more impaired in DLB compared to PD, highlighting the more aggressive nature of this atypical parkinsonian syndrome.

The editors of Clinical Autonomic Research hope that this issue fulfills its goals of raising awareness of and contributing to the knowledge of dysautonomia in the synucleinopathies, beyond blood pressure abnormalities, with the ultimate objective of improving the patients' quality of life.

\section{References}

1. Benarroch EE (2019) Multiple system atrophy: a disorder targeting the brainstem control of survival. Clin Auton Res (in press). https:// doi.org/10.1007/s10286-019-00643-7

2. Brandl SJ, Braune S (2018) Sensitivity and specificity of cardiac metaiodobenzylguanidine scintigraphy in the early diagnosis of Parkinson's disease. Clin Auton Res (in press). https://doi.org/10.1007/ s10286-018-0534-y
3. Carricarte Naranjo C, Marras C, Visanji NP, Cornforth DJ, SanchezRodriguez L, Schule B, Goldman SM, Estevez M, Stein PK, Lang AE, Jelinek HF, Machado A (2019) Increased markers of cardiac vagal activity in leucine-rich repeat kinase 2-associated Parkinson's disease. Clin Auton Res (in press). https://doi.org/10.1007/s1028 6-019-00632-w

4. Chen Y, Huang H, Ning P, Zhao Q, Wang H, Shen Q, Xu Y (2019) Frequency and factors related to drooling in Chinese patients with multiple system atrophy: a cross-sectional study. Clin Auton Res (in press). https://doi.org/10.1007/s10286-019-00602-2

5. Doi H, Sakakibara R, Masuda M, Tateno F, Aiba Y, Kishi M, Yamanishi T, Yamamoto T, Matsuoka K (2019) Gastrointestinal function in dementia with Lewy bodies: a comparison with Parkinson disease. Clin Auton Res (in press). https://doi.org/10.1007/s1028 6-019-00597-w

6. Donadio V (2018) Skin nerve alpha-synuclein deposits in Parkinson's disease and other synucleinopathies: a review. Clin Auton Res. (in press). https://doi.org/10.1007/s10286-018-0581-4

7. Hyam JA, Roy HA, Huang Y, Martin S, Wang S, Rippey J, Coyne TJ, Stewart I, Kerr G, Silburn P, Paterson DJ, Aziz TZ, Green AL (2019) Cardiovascular autonomic responses in patients with Parkinson disease to pedunculopontine deep brain stimulation. Clin Auton Res (in press). https://doi.org/10.1007/s10286-019-00634-8

8. Isonaka R, Gibbons C, Wang N, Freeman R, Goldstein DS (2019) Association of innervation-adjusted alpha-synuclein in arrector pili muscles with cardiac noradrenergic deficiency in autonomic synucleinopathies. Clin Auton Res (in press)

9. Macefield VG (2019) Where is the brain in all of this? Clin Auton Res. (in press). https://doi.org/10.1007/s10286-019-00601-3

10. Palma JA, Kaufmann H (2018) Treatment of autonomic dysfunction in Parkinson disease and other synucleinopathies. Mov Disord 33:372-390

11. Riboldi GM, Palma JA, Cortes E, Iida MA, Sikder T, Henderson B, Raj T, Walker RH, Crary JF, Kaufmann H, Frucht S (2019) Earlyonset pathologically proven multiple system atrophy with LRRK2 G2019S mutation. Mov Disord 34:1080-1082

12. Sakakibara R, Panicker J, Simeoni S, Uchiyama T, Yamamoto T, Tateno F, Kishi M, Aiba Y (2018) Bladder dysfunction as the initial presentation of multiple system atrophy: a prospective cohort study. Clin Auton Res (in press). https://doi.org/10.1007/s1028 6-018-0550-y

13. Sklerov M, Dayan E, Browner N (2018) Functional neuroimaging of the central autonomic network: recent developments and clinical implications. Clin Auton Res (in press). https://doi.org/10.1007/ s10286-018-0577-0

14. Stankovic I, Quinn N, Vignatelli L, Antonini A, Berg D, Coon E, Cortelli P, Fanciulli A, Ferreira JJ, Freeman R, Halliday G, Hoglinger GU, Iodice V, Kaufmann H, Klockgether T, Kostic V, Krismer F, Lang A, Levin J, Low P, Mathias C, Meissner WG, Kaufmann LN, Palma JA, Panicker JN, Pellecchia MT, Sakakibara R, Schmahmann J, Scholz SW, Singer W, Stamelou M, Tolosa E, Tsuji S, Seppi K, Poewe W, Wenning GK, Movement Disorder Society Multiple System Atrophy Study G (2019) A critique of the second consensus criteria for multiple system atrophy. Mov Disord 34:975-984

15. Vilas D (2019) Moving forward the in vivo diagnosis of the synucleinopathies. Clin Auton Res (in press). https://doi.org/10.1007/s1028 6-019-00595-y

16. Vilas D, Sharp M, Gelpi E, Genis D, Marder KS, Cortes E, Vonsattel JP, Tolosa E, Alcalay RN (2018) Clinical and neuropathological features of progressive supranuclear palsy in Leucine rich repeat kinase (LRRK2) G2019S mutation carriers. Mov Disord 33:335-338

17. Zhao Y, Dzamko N (2019) Recent developments in LRRK2-targeted therapy for Parkinson's disease. Drugs 79:1037-1051 